Jurnal Epidemiologi Kesehatan Komunitas

6 (1), 2021, 200-206

\title{
JEKK
}

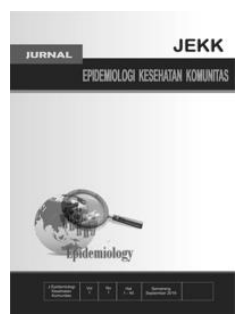

\section{Gambaran Profil dan Infeksi Cacing Usus pada Pekerja di Tiga Rumah Potong Hewan Provinsi Riau}

\author{
Esy Maryanti*, Yolazenia*, Afrinaldi ${ }^{* *}$, Fadly Mulia ${ }^{* *}$, Mislindawati* \\ * Bagian Parasitologi, Fakultas Kedokteran,Universitas Riau, Pekanbaru, Riau, Indonesia \\ ${ }^{* *}$ Program Studi Kedokteran, Fakultas Kedokteran ,Universitas Riau, Pekanbaru, Riau, Indonesia
}

\begin{abstract}
Background: Intestinal worm infestation is still a health problem in Indonesia that is often neglected. This disease is chronic in nature and is strongly influenced by factors of environmental hygiene and sanitation. Slaughterhouses are places where animals in the form of cows, goat/ sheep and pigs are slaughtered to be distributed to meat sellers or to reataurants. This study aims to determine the profil description and incidence of intestinal worm infestations in workers in three slaughterhouses in Riau Province.

Methods: This study was a cross-sectional descriptive study in August - October 2020 in three slaughterhouses in Riau Province (Pekanbaru, Duri and Dumai city). Stool examination was carried out using the Kato Katz Method at the Parasitology Laboratory Medical Faculty, Universitas Riau.

Result: Do A total 37 workers who were examined found 35 men, age range $21-30$ yo as much as $38 \%$ with latest education $46 \%$ was high school, length of work $1-5$ years as much as $57 \%$ and as much as $41 \%$ have normal nutriotional status. Six workers found positive for intestinal worm infections (16\%), there were three hookworm infections and one each to Trichuris trichiura, Oxyuris vermicularis and Hymenolepis diminuta.

Conclusion: There were still intestinal worm infections among workers in the three slaughterhouses. Intestinal worm infection usually occurs in children and rarely occurs in adults and if it occurs in adults this may be due to poor hygiene and sanitation of the slaughterhouse workers.
\end{abstract}

Keywords: intestinal worm ; Kato Katz ; slaughterhouse

*Penulis korespondensi : esy.maryanti@gmail.com 


\section{Pendahuluan}

Infeksi cacing usus masih merupakan masalah kesehatan di negara berkembang termasuk di Indonesia. Parasit ini sering terabaikan walaupun jarang bersifat fatal tetapi penyakit yang disebabkan oleh cacing usus ini dapat bersifat kronis dan menyebabkan tingginya angka morbiditas. ${ }^{1,-3}$ Morbiditas berhubungan dengan jumlah cacing yang menginfeksi manusia. Orang yang dengan infeksi intensitas ringan biasanya tidak bermanifestasi. Infeksi yang berat dapat menyebabkan berbagai gejala seperti diare, sakit perut, malnutrisi, malaise dan kelemahan umum. Pada infeksi dengan intensitas yang sangat berat yaitu jumlah cacing yang banyak di dalam tubuh dapat menyebabkan obstruksi usus oleh cacing sehingga memerlukan tindakan pembedahan. ${ }^{1,4}$ Pada orang dewasa infeksi parasit ini dapat menurunkan produktivitas kerja sedangkan pada anak dapat mengganggu tumbuh kembang. ${ }^{5-7}$

Berdasarkan data dari World Health Organization (WHO) didapatkan sekitar lebih dari dua milyar penduduk dunia terinfeksi cacing usus ini khususnya soil transmitted helminth. ${ }^{1,2}$ Meskipun infeksi cacing ini terutama berdampak pada anak tetapi parasit ini dapat menginfeksi seluruh kelompok usia ${ }^{1,4}$ Penelitian di Arkolinga, Cameroon tahun 2016 didapatkan angka kejadian soil transmitted helminths sebanyak $51,5 \%$ pada orang dewasa. ${ }^{8}$ Faktor risiko yang dapat mempengaruhi infeksi cacing usus ini antara lain status sosial ekonomi, kurangnya ketersediaan air bersih, sanitasi lingkungan yang tidak memadai dan higien personal yang masih kurang. ${ }^{1,2,6,9}$

Rumah potong hewan (RPH) adalah suatu bangunan atau kompleks bangunan dengan desain dan syarat tertentu yang digunakan sebagai tempat memotong hewan bagi konsumsi masyarakat umum. ${ }^{10} \mathrm{RPH}$ merupakan tempat pemotongan hewan berupa sapi, kerbau, kambing, babi dan unggas dipotong untuk disalurkan ke pasar-pasar ataupun penjual. Sebagian besar hewan tersebut merupakan hospes perantara ataupun hospes resorvoar dari parasit tesebut. Pekerja rumah potong hewan merupakan orang yang dapat berisiko terpapar dengan infestasi parasit ini. $^{11,12}$ Tujuan penelitian ini adalah untuk mengetahui angka kejadian infestasi cacing usus pada pekerja rumah potong hewan serta faktor-faktor yang mempengaruhinya.

\section{Metode}

Penelitian ini adalah penelitian deskriptif cross sectional yang dilakukan pada bulan Agustus - Oktober 2020 di tiga rumah potong hewan Provinsi Riau yaitu Kota Pekanbaru, Duri dan Dumai. Kriteria inklusi adalah pekerja yang terpapar langsung dengan hewan serta bersedia untuk dijadikan subyek penelitian. Pemeriksaan cacing usus diambil dari tinja pekerja rumah potong hewan dan pemeriksaan tinja dilakukan secara mikroskopis dengan pemeriksaan langsung menggunakan pewarnaan eosin dan Metode Kato Katz ${ }^{13}$ di Laboratorium Parasitologi Fakultas Kedokteran Universitas Riau. Pengambilan data kuesioner untuk karakteristik subyek penelitian dan faktor-faktor yang mempengaruhi infeksi cacing dilakukan dengan wawancara terpimpin. Status gizi subyek penelitian diukur berdasarkan indeks massa tubuh yang dikelompokkan jadi kurus, normal, overweight dan obesitas. ${ }^{14}$

\section{Hasil}

Karakteristik subyek penelitian yaitu sebanyak 37 pekerja yang diperiksa didapatkan 35 orang berjenis kelamin laki-laki. Rentang umur terbanyak yaitu $38 \%$ berumur $21-30$ tahun dengan pendidikan terakhir $46 \%$ adalah SMA dan lama bekerja 1- 5 tahun sebanyak $57 \%$. Status gizi pekerja sebanyak $41 \%$ adalah normal seperti yang terlihat pada tabel 1.berikut.

Tabel 1. Karakteristik Subyek Penelitian

\begin{tabular}{lcc}
\hline \multicolumn{1}{c}{ Variabel } & Jumlah & Persentase \\
\hline Jenis Kelamin & & \\
Laki-Laki & 35 & $95 \%$ \\
Perempuan & 2 & $5 \%$ \\
Umur & & \\
$\leq 20$ tahun & 5 & $13 \%$ \\
$21-30$ tahun & 14 & $38 \%$ \\
\hline
\end{tabular}




\begin{tabular}{lcc}
\hline \multicolumn{1}{c}{ Variabel } & Jumlah & Persentase \\
\hline 31 - 40 tahun & 8 & $22 \%$ \\
$>40$ tahun & 10 & $27 \%$ \\
Pendidikan Terakhir & & \\
SD & 9 & $24 \%$ \\
SMP & 3 & $8 \%$ \\
SMA & 17 & $46 \%$ \\
Sarjana & 8 & $22 \%$ \\
Lama Bekerja & & \\
$<1$ tahun & 3 & $8 \%$ \\
1 - 5 tahun & 21 & $57 \%$ \\
$6-10$ tahun & 5 & $13 \%$ \\
$>10$ tahun & 8 & $22 \%$ \\
Status Gizi & & \\
Kurus & 7 & $19 \%$ \\
Normal & 15 & $41 \%$ \\
Overweight & 9 & $24 \%$ \\
Obesitas & 6 & $16 \%$ \\
\hline
\end{tabular}

Pada pekerja didapatkan sebanyak enam orang positif infeksi cacing usus (16\%) yaitu infeksi cacing tambang sebanyak tiga orang, Trichuris trichiura, Oxyuris vermicularis dan Hymenolepis diminuta masing-masing sebanyak satu orang. Pada penelitian ini tidak didapatkan infeksi cacing pita Taenia $s p$. Faktor-faktor yang mempengaruhi infeksi cacing usus dapat dilihat pada tabel. 2 berikut.

Tabel 2. Faktor-faktor yang mempengaruhi infeksi cacing usus

\begin{tabular}{lcc}
\hline \multicolumn{1}{c}{ Variabel } & N & $\%$ \\
\hline Mencuci tangan setelah bekerja & & \\
$\quad$ Ya & 37 & $100 \%$ \\
Tidak & 0 & $0 \%$ \\
Mencuci tangan sebelum makan & & \\
Ya & 37 & $100 \%$ \\
Tidak & 0 & $0 \%$ \\
Mencuci tangan setelah BAB & & \\
$\quad$ Ya & 37 & $100 \%$ \\
Tidak & 0 & $0 \%$ \\
Mencuci tangan dengan sabun & & \\
$\quad$ Ya (air dan Sabun) & 33 & $89,19 \%$ \\
$\quad$ Tidak (air saja) & 4 & $10,81 \%$ \\
Menggunting kuku min 1x & & \\
seminggu & & \\
$\quad$ Ya & 33 & $89,19 \%$ \\
\hline
\end{tabular}

\begin{tabular}{lcc}
\hline \multicolumn{1}{c}{ Variabel } & $\mathbf{N}$ & $\mathbf{\%}$ \\
\hline Tidak & 4 & $10,81 \%$ \\
Pernah makan sambil bekerja & & \\
Ya & 12 & $32,43 \%$ \\
Tidak & 25 & $67,57 \%$ \\
Pernah makan daging mentah & & \\
Ya & 1 & $2,70 \%$ \\
Tidak & 36 & $97,30 \%$ \\
$\begin{array}{l}\text { Pernah gatal-gatal di anus dan } \\
\text { keluar serpihan putih yang }\end{array}$ & & \\
bergerak-gerak di anus & & \\
$\quad$ Ya & 1 & $2,70 \%$ \\
Tidak & 36 & $97,30 \%$ \\
\hline
\end{tabular}

Berdasarkan Tabel 2 didapatkan semua pekerja selalu mencuci tangan setelah bekerja, sebelum makan dan setelah buang air besar tetapi ditemukan sebanyak 4 orang pekerja yang tidak selalu memakai sabun ketika mencuci tangan di tiga kegiatan tersebut. Prilaku menggunting kuku sebagian besar sudah baik $(89,19 \%)$. Makan atau ngemil atau merokok sambil bekerja sebanyak 32,43\% pekerja pernah melakukan dan sebanyak satu orang pekerja pernah makan daging mentah. Selain itu juga ditemukan bahwa semua pekerja memakai alat pelindung diri (APD) ketika bekerja tetapi APD yang dipakai tidak selalu lengkap yaitu sarung tangan, sepatu boot, masker dan baju lengan panjang.

\section{Pembahasan}

Penelitian ini menggambarkan karakteristik pekerja di tiga rumah potong hewan Provinsi Riau yaitu Kota Pekanbaru, Duri dan Dumai. Sebanyak 37 pekerja didapatkan umumnya pekerja adalah berjenis kelamin laki-laki dan terbanyak berumur $21-$ 30 tahun. Rumah potong hewan merupakan tempat pemotongan hewan untuk didistribusikan ke masyarakat. Pekerja pada rumah potong hewan adalah orang yang bekerja untuk pemotongan hewan sesuai dengan prosedur ${ }^{10,11}$ dan pekerjaan ini membutuhkan tenaga yang memang sesuai untuk laki-laki. Untuk pendidikan terakhir pekerja lebih banyak pekerja dengan pendidikan SMA walaupun juga ada yang tamat SD. Pekerjaan untuk memotong hewan 
ini tidak memerlukan kualifikasi pendidikan yang tinggi tetapi pekerja harus dapat bekerja sesuai dengan prosedur yang digunakan. Umumnya pekerja sudah bekerja lebih dari satu tahun. Infeksi cacing usus ini bersifat kronis, mulai dari individu terinfeksi dengan telur atau larva cacing sampai cacing dewasa di dalam tubuh memerlukan waktu berbulan - bulan tergantung pada spesies cacing yang menginfeksi. ${ }^{4,15}$ Cacing pita sapi yang dapat menyebabkan penyakit taeniasis saginata dan cacing pita babi yang dapat menyebabkan taeniasis solium dan sistiserkosis pada manusia dapat hidup bertahun-tahun dalam tubuh manusia yang terinfeksi. ${ }^{(16-20)}$ Status gizi pekerja sebagian besar normal, status gizi dapat mempengaruhi infeksi cacing. Pada individu dengan status gizi yang kurang, infeksi cacing dapat berakibat buruk sedangkan pada status gizi yang normal atau baik dan bila didukung oleh imunitas yang juga baik maka infeksi cacing dapat asimptomatis dan bahkan bisa sembuh sendiri apabila derajat infeksi cacing sangat ringan dan juga tergantung kepada spesies cacing yang menginfeksi manusia tersebut. ${ }^{1,4,21}$

Hasil pemeriksaan tinja pada penelitian ini didapatkan sebanyak 6 orang pekerja (16\%) yang terinfeksi cacing usus. Pemerintah menetapkan prevalensi cacing usus kurang dari $20 \%$ digolongkan pada kategori rendah tetapi ini ditetapkan untuk daerah kota atau kabupaten. ${ }^{2}$ Jenis cacing yang didapatkan pada penelitian ini adalah cacing tambang, Trichuris trichiura, Oxyuris vermicularis dan Hymenolepis diminuta. Cacing tambang dan T.trichiura merupakan soil transmitted helminths. Soil transmitted helminths atau cacing yang penularannya melalui tanah merupakan cacing usus yang memerlukan tanah untuk mematangkan telurnya menjadi bentuk infektif sehingga dapat menginfeksi manusia. $^{4,22}$ Biasanya infeksi cacing usus ini mengenai usia anak tetapi tentu juga dapat mengenai dewasa apabila mengenai dewasa berarti faktor higienitas dan sanitasi terutama akses ataupun kesediaan air bersih yang masih kurang di lingkungan tempat tinggal ataupun tempat bekerja individu tersebut. ${ }^{1,23}$

Oxyuris vermicularis merupakan nematoda usus yang bukan termasuk soil transmitted helminth. Manusia merupakan satu-satunya hospes definitif cacing ini. ${ }^{4}$ Jika pekerja rumah potong hewan terinfeksi cacing ini berarti tidak ada hubungannya paparan hewan yang dipotong. Manusia terinfeksi cacing ini karena tertelan dengan telur matang atau bila larva dari telur yang menetas di daerah perianal berimigrasi kembali ke usus besar. Telur matang yang tertelan berhubungan dengan personal higien yang kurang yaitu kebiasaan tidak mencuci tangan sebelum makan atau sering memasukkan jari ke mulut dan cebok yang tidak bersih. Infeksi cacing ini bila ringan dapat sembuh sendiri tanpa pengobatan. ${ }^{4,24}$ Pada penelitian ini juga didapatkan infeksi cacing Hymenolepis diminuta pada seorang pekerja. Infeksi oleh H.diminuta jarang terjadi, cacing ini merupakan cacing pita tikus dan manusia yang hospes perantaranya dalah pinjal tikus. Bila pinjal tikus yang mengandung larva $H$.diminuta termakan oleh manusia maka manusia akan terinfeksi oleh cacing ini. Adanya infestasi cacing ini menandakan higienitas dan sanitasi yang masih kurang dari individu tersebut. (25-27)

Pada penelitian ini didapatkan semua pekerja sudah mencuci tangan sesudah bekerja, sebelum makan dan sesudah buang air besar tetapi memang ada sebagian kecil pekerja yang mencuci tangan tidak selalu dengan sabun. Cuci tangan yang bersih dengan sabun merupakan salah satu tindakan pencegahan untuk infeksi cacing usus yang penularannya lewat fecal-oral. Menggunting kuku sekali seminggu juga merupakan salah satu tindakan pencegahan infeksi cacing usus karena kuku yang panjang dapat menyimpan telur cacing dan bila makan dengan tangan maka telur cacing tersebut akan tertelan bersama makanan. ${ }^{28}$

Infeksi cacing pita Taenia spp. tidak ditemukan pada pekerja RPH yang diperiksa. Pekerja rumah potong hewan yang selalu terpapar dengan daging sapi ataupun daging babi merupakan orang yang dapat berisiko untuk terinfeksi cacing pita Taenia spp. bila higien personal dan lingkungan tempat kerja tidak diperhatikan. ${ }^{16,17,29}$ Pada penelitian ini umumnya pekerja RPH tidak pernah termakan daging mentah dan tidak pernah mempunyai gejala taeniasis seperti keluarnya serpihan 
berwarna putih yang bergerak-gerak dari anus yang merupakan proglotid gravid yang lepas walaupun pemakaian APD pekerja tidak selalu lengkap.

\section{Kesimpulan}

Pada tiga RPH didapatkan umumnya pekerja berjenis kelamin laki-laki dengan umur terbanyak 21 - 30 tahun, pendidikan terakhir SMA, lama bekerja $1-5$ tahun dan status gizi normal. Infeksi cacing usus didapatkan pada 6 orang pekerja (16\%) dengan jenis cacing yang ditemukan yaitu cacing tambang, Trichuris trichiura, Oxyuris vermicularis dan Hymenolepis diminuta.

\section{Ucapan Terimakasih}

Penulis mengucapkan terimakasih kepada kepala beserta staf Rumah Potong Hewan Provinsi Riau atas ijin dan fasilitas yang diberikan selama penelitian.

\section{Daftar Pustaka}

1. World Health Organization. 2020. Soil Transmitted helminthiases. Available: https://www.who.int/health-topics/soiltransmitted-helminthiases\#tab=tab_1

2. Kementerian Kesehatan Republik Indonesia. 2017. Peraturan Menteri Kesehatan Republik Indonesia No.15 Tahun 2017 Tentang Penanggulangan Cacingan..

3. Siagian FE, Maryanti E. 2020. Anemia and other blood symptoms related soil transmitted helminthiasis: An internet approach of systematic literature study reported across Indonesia. International Blood Research and Reviews. 11 (3): 3447.

4. Supali T. Margono SS, Abidin SAN. Nematoda. Dalam: Sutanto I, Ismid IS. Sjarifuddin PK, Sungkar S. 2015. Penyunting. Buku ajar parasitologi kedokteran. Edisi keempat. Jakarta: Badan Penerbit FKUI..h.6-25.
5. Siregar CD. 2006. Pengaruh infeksi cacing usus yang ditularkan melalui tanah pada pertumbuhan fisik anak usia sekolah dasar. Sari Pediatri. 8 (2): 112-117.

6. Novianty S. Pasaribu HS. Pasaribu AP. 2018. Faktor risiko kejadian kecacingan pada anak usia pra sekolah. J Indo Med Assoc.; 68 (2): 86 - 92.

7. Kurniawan A. 2011. Meningkatkan kewaspadaan dokter terhadap infeksi parasit intestinal pada anak. J Indon Med Assoc. 61 (9): 345-6.

8. Bopda J, Nana-Jeunga $\mathrm{H}$, Tenaguem $\mathrm{J}$, Kamtchum-Tatuene J, Gounbue-Kamkumo R, Assob-Nguedia C, et al. 2016. Prevalence and intensity of human soil transmitted helminth infections in the Akonolinga health districth (Centre Region, Cameroon); Are adult hosts contributing in the persistence of the transmission?. Parasite Epidemiology and Control. 1: 199204.

9. Steinbaum L, Mboyu J, Mahoney R, Njengu SM, Null C, Pickering AJ. 2019. Effect of a sanitation intervention on soil transmitted helminth prevalence and concentration in household soil: a clusterrandomized controlled trial and risk factor analysis. Plos Neglected Tropical Disease. 1- 17.

10. Kementerian Pertanian Republik Indonesia. 2010. Peraturan Menteri Pertanian Republik Indonesia No.13 Tahun 2010 Tentang Persyaratan rumah potong hewan ruminansia dan unit penanganan daging (meat cutting plant).

11. Tolistiawaty I, Widjaja J, Isnawati R, Lobo LT. 2015. Gambaran rumah potong hewan/ tempat pemotongan hewan di Kabupaten Sigi, Sulawesi Tengah. Jurnal Vektor Penyakit. 9 (2): 45-52.

12. Gaznur Zm, Nuraini H, Priyanto R. 2017. Evaluasi penerapan standar sanitasi dan 
higien di rumah potong hewan kategori II. Jurnal Veteriner. 18 (1): 107-115.

13. World Health Organization. 1991. Basic laboratory methods in medical parasitology. WHO Press. Geneva.

14. Ditjen Bina Kesehatan Masyarakat. 2003. Pedoman praktis terapi gizi medis. Jakarta: Ditjen Bina Kesehatan Masyarakat. Departemen Kesehatan RI.

15. Margono SS, Hadidjaja P. 2011. Penyakit yang disebabkan helmint. Dalam: Hadidjaja P, Margono SS. Penyunting. Dasar Parasitologi Klinik. Edisi pertama. Jakarta: Badan Penerbit FKUI. h.121-57.

16. Syarifah N. 2009. Penyakit oleh cestoda usus. Dalam: Natadisastra D, Agoes R, Penyunting. Parasitologi kedokteran ditinjau dari organ tubuh yang diserang. Jakarta: EGC. h.110-20.

17. Wandra T, Margono SS, Gafar MS, Saragih JM, Sutisna P, Sudewi AAR, et al. 2007. Current situation of taeniasis and cysticercosis in Indonesia. Tropical Medicine and Health. 35 (4): 323 -8.

18. Boston J. 2012. Intestinal Tapeworms in D. Greenwood. Medical Microbiology.

19. Sato MO, Sato M, Yanagida T, Waikagul J, Pongvongsa T, Sako Y, et al. 2018. Taenia solium, Taenia saginata, Taenia asiatica, their hybrids and other helminthic infections occuring in a neglected tropical diseases highly endemic area in Lao PDR. Plos Neglected Tropical Diseases. 12(2).

20. Kumar K, Kumari K, Praveen PK, Ganguly S. 2016. Taeniasis a significant parasitic zoonotic disease: a critical review. International Journal of Science Environment and Technology. 5 (6): 3843 -6 .
21. Moncayo AL, Lovato R, Cooper PJ. 2018. Soil transmitted helminth infections and nutritional status in Equador: findings from a national survey and implications for control strategies. British Medical Journal. 8.

22. CDC. 2013. Parasites-Soil transmitted helminths. Global health division of Parasitic Diseases and Malaria. Available: https://www.cdc.gov/parasites/sth/index.ht $\mathrm{ml}$.

23. Periago MV, Garcia R, Astudillo OG, Cabrera M, Abril MC. 2018. Prevalence of intestinal parasites and the absence of soil transmitted helminths in Anatuya, Santiago del Estero, Argentina. Parasites \& Vektors. 11: 638 .

24. Rawla P, Sharma S. 2020. Enterobius vermicularis. 2020. Stat Pearls [Internet]. Treasure Island: StatPearls Publishing; 2 Available:

https://www.ncbi.nlm.nih.gov/books/NBK5 36974/\#article-27237.s5

25. Fitte B, Robbles MdR, Unzaga JM, Dellarupe R, Navone GT. 2017. Hymenolepis diminuta and Rodentolepis nana (Hymenolepididae: Cyclophyllidea) in urban rodents of Gran La Plata: association with socio-environmental conditions. Journal of Helminthology.: 92 (5): 1-5.

26. Marbawati D. 2010. Hymenolepis sp, Cacing Pita Parasit Pada Tikus dan Manusia. Balaba: 6(2): 24-25.

27. Panti-May JA, Rodriguez-Vivas RI, Garcia-Prieto L, Servian A, Costa F. 2020. Worldwide overview of human infections with Hymenolepis diminuta. Parasitol Res. 119(7): 1997-2004.

28. Wintoko R. 2014. Relations aspects of personal hygiene and behavior aspect with worm eggs nail contamination risk at 4,5,6 grade state ES 2 Raja Basa District Bandar Lampung Academic Year 2012/2013. 
Jurnal Kedokteran Universitas Lampung. 4 (7): 136-41.

29. Handojo I, Margono SS. 2008.

Cyclophyllidea. In: Sutanto I, Ismid IS, Sjarifuddin PK, Sungkar S, editors,

Parasitologi Kedokteran. Jakarta: Balai

Penerbit FKUI. p.78 - 86. 